\title{
Alzheimer's Disease Phenotype or Inflammatory Insult Does Not Alter Function of L-Type Amino Acid Transporter I in Mouse Blood-Brain Barrier and Primary Astrocytes
}

\author{
Mikko Gynther' - Elena Puris ' - Soile Peltokangas' - Seppo Auriola' • Katja M. Kanninen ${ }^{2}$. \\ Jari Koistinaho ${ }^{2} \cdot$ Kristiina M. Huttunen ' $^{\prime}$ Marika Ruponen ' Kati-Sisko Vellonen '
}

Received: 25 September 2018 / Accepted: 18 November 2018 / Published online: 28 November 2018

(C) The Author(s) 2018

\begin{abstract}
Purpose The study aim was to evaluate the effect of Alzheimer's disease (AD) and inflammatory insult on the function of L-type amino acid transporter 1 (Latl) at the mouse blood-brain barrier (BBB) as well as Latl function and expression in mouse primary astrocytes.

Methods The Latl function and expression was determined in wildtype astrocytes with and without lipopolysaccharide (LPS)-induced inflammation and in LPS treated AD APP/PS/ transgenic astrocytes. The function of Latl at the BBB was evaluated in wildtype mice with and without LPS-induced neuroinflammation and APP/PS/ transgenic mice by in situ brain perfusion.
\end{abstract}

Results There were 2.1 and 1.6 -fold decreases in Lat1 mRNA and protein expression in LPS-treated wildtype astrocytes compared to vehicle-treated astrocytes. In contrast, Lat 1 mRNA and protein expression were increased by 1.7 and 1.2 fold (not statistically significant) in the transgenic cells. A similar trend was observed in the cell uptake of $\left[{ }^{14} \mathrm{C}\right]$-L-leucine. There were no statistically significant differences in $\left[{ }^{14} \mathrm{C}\right]-\mathrm{L}$ leucine BBB permeation between the groups.

Conclusions The results showed that neither LPS-induced inflammation or the presence of APP/PS / mutations alters Latl function at the mouse BBB as well as Latl protein expression and function in mouse primary astrocytes.

KEY WORDS alzheimer's disease · blood-brain barrier . CNS drug delivery · L-type amino acid transporter

Mikko Gynther

Mikko.gynther@uef.fi

School of Pharmacy, University of Eastern Finland, P.O. Box 1627 Fl-702II Kuopio, Finland

2 A.I. Virtanen Institute for Molecular Sciences, University of Eastern Finland, Fl-702II Kuopio, Finland

$\begin{array}{ll}\text { ABBREVIATIONS } \\ \text { AB } & \beta \text {-amyloid } \\ \text { AD } & \text { Alzheimer's disease } \\ \text { BBB } & \text { Blood-brain barrier } \\ \text { CNS } & \text { Central nervous system } \\ \text { LatI } & \text { L-type amino acid transporter 1 } \\ \text { LC-MS/MS } & \text { Liquid chromatography mass spectrometry } \\ \text { LPS } & \text { Lipopolysaccharide } \\ \text { MRM } & \text { Multiple reaction monitoring }\end{array}$

\section{INTRODUCTION}

One of the major challenges in the development of new drugs for central nervous system (CNS) disorders such as Alzheimer's disease (AD) is the delivery of the drug molecules into the site of action. (1) The blood-brain barrier (BBB) protects the brain efficiently by controlling the movement of solutes from blood to brain by the means of enzymes, transporters and tight junctions between the endothelial cells. In addition, transporter proteins expressed in brain parenchyma have a deciding role in the intra-brain distribution of drugs. $(2,3)$ This complicates the CNS drug delivery and can hinder the development of efficient drug therapies. (4) There is a great need for drug delivery technologies across the BBB and into the target cells. One approach to overcome the $\mathrm{BBB}$ is to design drugs or prodrugs capable of utilizing influx transporters highly expressed at the BBB. (4) The same transporter can be used to reach the target cells in the brain parenchyma. The prerequisite for transporter mediated drug delivery approach is, however, profound knowledge of transporter expression and function in the diseased brain (5).

L-type amino acid transporter 1 (Latl) is a heterodimeric transporter protein capable of transporting neutral, large and branched amino acids, such as leucine and tryptophan, across the cell membrane. (6) In addition, Latl has been shown to transport many CNS drugs, such as L-DOPA and gabapentin 
across the BBB into the brain. $(7,8)$ Moreover, there are numerous reports of Latl being utilized for the delivery of prodrugs of CNS acting agents into the mouse or rat brain and into the intracellular compartment of brain parenchyma. (9-12) Latl is expressed on both luminal and abluminal brain capillary membranes and the membrane of cells within the brain parenchyma. $(13,14)$ This enables Latl-utilizing compounds to cross not only the BBB but also to penetrate cell membranes in the brain. However, there are concerns whether influx transporters, in particular Latl, retain sufficient expression and function in the brain and BBB in neuropathological conditions. For example, glucose transporter type 1 (GLUT1/Glut1) is downregulated in brain parenchymal cells and the $\mathrm{BBB}$ of $\mathrm{AD}$ patients and $\mathrm{AD}$ mouse models. (15-17) In Parkinson's disease, the usefulness of L-DOPA, an Lat1 utilizing prodrug of dopamine, proves that the Latl transporter function remains efficient despite the disease. (7) However, the expression and function of Latl transporter in the BBB and brain parenchyma suffering from $\mathrm{AD}$ and neuroinflammation has not been explored in the literature extensively.

In order to investigate the effect of $\mathrm{AD}$ on Latl expression, an $A P P / P S 1$ transgenic mouse model with mutations in genes encoding amyloid precursor protein $(A P P)$ and presenilin (PSEN1) was utilized. (18) The effects of the mutations on Lat 1 expression and function at the BBB and astrocytes are sparse. Vellonen et al. (19) recently reported the mRNA expression of Latl in APP/SPS1 mouse brain capillaries and no significant differences were found compared to wildtype control mice. However, neither Latl protein expression nor function were investigated in that study. There exists a recent report of reduced expression of Latl in CNS disease models of neuroinflammation. (20) The results demonstrated that LPSinduced inflammation rapidly decreased Lat $1 \mathrm{mRNA}$ expression at the BBB of male mice and rats, while changes in Lat 1 protein level followed a slower kinetics. Importantly, the effect of LPS-induced neuroinflammation on the function of Latl at the mouse BBB has not been studied.

Astrocytes control the brain ion homeostasis, regulate $\mathrm{pH}$ and blood flow in brain. In addition, astrocytes have important neuro-supportive role as they contribute to synaptogenesis, synaptic transmission, synaptic structural integrity. (21) Importantly, astrocytes play a significant role in the development of $\mathrm{AD}$. As several target proteins for potential $\mathrm{AD}$ drugs reside inside the astrocytes, it makes the transporter expression in these cells of great interest in terms of drug delivery. (21) Moreover, as Latl has a significant role in the intra-brain distribution of its substrates, $(9,22,23)$ it is important to elucidate whether the Latl expression and function are altered in astrocytes due to existing inflammation or $\mathrm{AD}$ transgene expression. The decreased transporter function at the BBB and in the target cells due to low protein expression would mitigate the utilization of Latl for brain drug delivery in neurodegenerative diseases such as $\mathrm{AD}$.
The aim of the present study was to investigate whether LPS-induced acute inflammation or the presence of $\mathrm{AD}$ causing mutations in $A P P$ and $P S 1$ genes affect the function of Latl at the mouse BBB, as well as the Lat 1 mRNA and protein expression and function in primary mouse astrocytes. The Latl function at the BBB of wildtype, LPS-treated and $\mathrm{AD}$ transgenic mice was investigated by measuring the $\mathrm{BBB}$ permeation rate via unidirectional transfer constant $\left(\mathrm{K}_{\mathrm{in}}\right)$ of Latl substrate $\left[{ }^{14} \mathrm{C}\right]$-L-leucine using the in situ mouse brain perfusion technique. The Latl function in wildtype astrocytes as well as wildtype and $\mathrm{AD}$ transgenic astrocytes treated with LPS was determined and $\left[{ }^{14} \mathrm{C}\right]$-L-leucine $\mathrm{K}_{\mathrm{m}}$ and $\mathrm{V}_{\max }$ values calculated. In addition, the Lat1 1 protein expression in the astrocytes was quantified by liquid chromatography-mass spectrometry (LC-MS/MS)-based proteomics.

\section{MATERIALS AND METHODS}

\section{Animals}

Mice carrying human APP (K595 N and M596 L) and PSEN1dE9 mutations maintained in C57BL/6 J background were used as a mouse model of AD (18) Jackson Laboratories, Bar Harbor, ME, USA). These mice are referred to as APP/ PS1 mice. A $\beta$ plaques appear in this model from approximately the age of four-five months and animals were used for the experiments between the ages of 7 to 8 months. Age-matching C57BL/6 J strain wildtype mice were used as controls. LPS treated mice were of the C57BL/6JOIaHsd strain and were 12 weeks old at the time of the experiments. The animals were kept in controlled environment with $12 \mathrm{~h}$ light/dark cycle and food and water freely available. The animal studies were performed according to the Council of Europe (Directive 86/ 609) and Principles of laboratory Animal Care. Studies were approved by the local committee of animal experiments (ESAVI/3347/04.10.07/2015).

\section{In Situ Mouse Brain Perfusion}

Mice were anesthetized with intraperitoneal (i.p.) injections of ketamine $(120 \mathrm{mg} / \mathrm{kg})$ and xylazine $(8 \mathrm{mg} / \mathrm{kg})$, and their right carotid artery system was exposed. The right external carotid artery was ligated, and the right common carotid artery was cannulated with a catheter filled with $100 \mathrm{IU} / \mathrm{mL}$ heparin. The perfusions were performed at $37^{\circ} \mathrm{C}$ with a flow rate of $2.5 \mathrm{~mL} /$ min for $30 \mathrm{~s}$ followed by the washing of the capillaries for $2 \mathrm{~s}$ with $4^{\circ} \mathrm{C}$ drug-free perfusion buffer. The function of Latl at the BBB was evaluated by perfusing $0.157 \mu \mathrm{M}\left[{ }^{14} \mathrm{C}\right]$-L-leucine (PerkinElmer, Waltham, MA, USA) as a known Latl probe substrate. The Latl function was assessed in APP/PS1 transgenic mice, wildtype control mice and wildtype mice injected with $250 \mu \mathrm{g} / \mathrm{kg}$ (i.p.) of LPS once a day for three days followed 
by the brain perfusion performed $24 \mathrm{~h}$ after the final injection. In addition, a group of wildtype mice without LPS treatment were perfused with a combination of $\left[{ }^{14} \mathrm{C}\right]$-L-leucine and $100 \mu \mathrm{M}$ of selective Latl inhibitor (S)-2-Amino-3-(3-((2,4dicyano-3-(4-(2-(methylamino)-2oxoethoxy)phenyl)benzo $(3,5)$ imidazo[1,2-a]pyridin-1-yl)-carbamoyl)phenyl)propanoic acid (KMH-233). (24) After the brain perfusion the hippocampus and cerebral cortex of the right cerebral hemisphere were collected and the $\mathrm{K}_{\text {in }}$ of $\left[{ }^{14} \mathrm{C}\right]$-L-leucine was determined (10).

\section{Astrocyte Cultures}

Primary astrocytes were isolated from 2-day-old wildtype and APP/PS1 mice and cultured as described earlier. (25) Shortly, cortices and hippocampi were isolated and the tissue was suspended into DMEM medium (Fisher Scientific GmbH, Schwerte, Germany) containing 10\% heat-inactivated fetal bovine serum (Fisher Scientific GmbH, Schwerte, Germany) and $100 \mathrm{U} / \mathrm{mL}$ penicillin streptomycin (Fisher Scientific $\mathrm{GmbH}$, Schwerte, Germany). The suspension was triturated ten times and thereafter centrifuged $1500 \mathrm{rpm}$ for $5 \mathrm{~min}$ at room temperature. Trypsin-EDTA (Fisher Scientific GmbH, Schwerte, Germany) of $0.25 \%$ was added and the suspension was incubated for $30 \mathrm{~min}$ at $37^{\circ} \mathrm{C}$. Fresh culture medium was added and the suspension was centrifugated $1500 \mathrm{rpm}$ for $5 \mathrm{~min}$. The cells were plated onto the poly-L-lysine (SigmaAldrich, Darmstadt, Germany) coated flasks in culture medium. To remove microglia, the cultures were shaken at $200 \mathrm{rpm}$ for $2 \mathrm{~h}$ before cells were used for experiments.

For uptake experiments the astrocytes (passage 7-16) were seeded on 24-well plates $\left(10^{4}\right.$ cells/well $)$ three days before experiments. The cells were cultured at $37^{\circ} \mathrm{C}, 5 \% \mathrm{CO}_{2}$ in culture medium (Gibco, DMEM/F12, Fisher Scientific $\mathrm{GmbH}$, Schwerte, Germany) containing 10\% heatinactivated fetal bovine serum and $100 \mathrm{U} / \mathrm{mL}$ penicillin streptomycin). When effect of inflammation was studied, the cells were exposed to $100 \mathrm{ng} / \mathrm{mL}$ LPS (Sigma-Aldrich, Darmstadt, Germany) for $24 \mathrm{~h}$ before the uptake experiment.

\section{Uptake Experiment}

Astrocytes were preincubated with washing buffer (Gibco HBSS, Schwerte, Germany), 25 mM Hepes (Sigma-Aldrich, Darmstadt, Germany), pH 7.4 for $10 \mathrm{~min}$ at $37^{\circ} \mathrm{C}$. Washing buffer was replaced by the reaction buffer (HBSS, $25 \mathrm{mM}$ Hepes, pH 7.4 containing $0.25 \mu \mathrm{Ci} / \mathrm{mL}\left[{ }^{14} \mathrm{C}\right]$-L-leucine (PerkinElmer, Inc., Waltham, MA, USA) and incubated for $2.5 \mathrm{~min}$ at $37^{\circ} \mathrm{C}$. Thereafter, the cells were washed three times with ice-cold buffer and lysed using $0.1 \mathrm{~N} \mathrm{NaOH}$ for $60 \mathrm{~min}$. The cell lysate was mixed with Ultima Gold scintillation cocktail (PerkinElmer, Inc., Waltham, MA, USA) and radioactivity was measured with MicroBeta liquid scintillation counter (Wallac Oy, Finland). The protein concentration of the samples was determined using Bio-Rad protein assay (BioRad Laboratories, Germany). Experiments were repeated 3-4 times with 3 parallel samples.

Inhibition of $\left[{ }^{14} \mathrm{C}\right]$-L-leucine uptake was studied by adding $2 \mathrm{mM}$ tryptophan to the reaction buffer. In the experiments where concentration dependent uptake of L-leucine was studied, desired concentration of non-labeled L-leucine (1$400 \mu \mathrm{M}$ ) was added to the reaction buffer. The lowest concentration contained $0.05 \mu \mathrm{Ci} / \mathrm{mL}$ of $\left[{ }^{14} \mathrm{C}\right]$-L-leucine.

\section{Quantitative RT-PCR}

The mRNA expression of Lat1 (Slc7a5 gene) was investigated in astrocytes isolated from wildtype and APP/PS1 transgenic mice. RNA was extracted with RNeasy Micro Kit (Qiagen, Germany) according to manufacturer's protocol. DNase treatment was done with DNA-free kit (Ambion, USA) and RNA concentration was measured with NanoVue (GE Healhcare, UK). RNA of $200 \mathrm{ng}$ was transcribed into cDNA by using M-Mulv reverse transcriptase and random primers (Fermentas, USA). cDNA corresponding to $4 \mathrm{ng}$ of RNA was amplified using SYBR Green chemistry, primers designed for Slc7a5 (forward CTCCTTGCGCATTG TCACAC, reverse GGACATGACACGCAAGTGGTAG) and ABI Prism 7500 (Applied Biosystems, UK). Melting curve analysis was performed after amplification cycles in order to check the specificity of amplification. Gapdh Endogenous Control (Applied Biosystems, UK) was used for normalization of Slc7a5 expression. Normalized expression was calculated with the QGene application using amplification efficiency determined for the Slc7a5 primer pair (26).

\section{Transporter Protein Quantitation from Astrocyte Crude Membrane Fractions}

ProteoExtract Subcellular Proteome Extraction Kit (Merck KGaA, Darmstadt, Germany) was used for the isolation of crude membrane fraction from the cell pellets of astrocytes following the manufacturer's instructions. The protein concentrations in the crude membrane fractions were determined as mean of three samples by Bio-Rad Protein Assay (EnVision, PerkinElmer, Inc., Waltham, MA, USA), and aliquots containing $50 \mu \mathrm{g}$ of total protein were taken for further sample preparation.

\section{Quantitative Protein Expression of Lat I and Glut I with Multiple Reaction Monitoring (MRM) by LC - MS/MS}

The protein expression of Lat 1 and Glut 1 in mouse wildtype and $\mathrm{AD}$ transgenic astrocytes was quantified by means of multiplexed MRM analysis according to the protocol described by Uchida et al., 2013. (27) Briefly, the aliquots of crude membrane cell fractions containing $50 \mu \mathrm{g}$ of protein 
were solubilized in $500 \mathrm{mM}$ Tris- $\mathrm{HCl}$ (pH 8.5), 7 M guanidine hydrochloride and $10 \mathrm{mM}$ EDTA. Consequently, the proteins were $S$-carbamoylmethylated with dithiothreitol followed by iodoacetamide treatment. After alkylation, the proteins were precipitated with methanol and chloroform. The dissolution of precipitates was performed by addition of $6 \mathrm{M}$ urea dissolved in $100 \mathrm{mM}$ Tris- $\mathrm{HCl}$ (pH 8.5) followed by 5-fold dilution with $0.1 \mathrm{M}$ Tris- $\mathrm{HCl}(\mathrm{pH} 8.5)$ spiked with internal standard peptide (JPT Peptide Technologies $\mathrm{GmbH}$, Berlin, Germany). After treatment with ProteaseMax surfactant (Promega, Madison, WI, USA) and digestion with lysyl endopeptidase (Lys-C: Wako Pure Chemical Industries, Osaka, Japan) at $30^{\circ} \mathrm{C}$ for $3 \mathrm{~h}$, tosylphenylalanyl chloromethyl ketone-treated trypsin (Promega, Madison, WI, USA) was added into the samples (enzyme/substrate ratio of 1:100). For tryptic digestion samples were incubated at $37^{\circ} \mathrm{C}$ for $16 \mathrm{~h}$. Before LC - MS/MS analysis, the digests were acidified with $20 \%(v / \mathrm{v})$ formic acid in water and centrifuged at $15000 \times \mathrm{g}$ for $5 \mathrm{~min}$ at $4^{\circ} \mathrm{C}$.

LC - MS/MS analysis was conducted using an Agilent 1290 Infinity LC (Agilent Technologies, Waldbronn, Germany) instrumentation coupled to an Agilent 6495 Triple Quadrupole Mass Spectrometer equipped with an electrospray ionization (ESI) source (Agilent Technologies, Palo Alto, CA, USA). The peptides were separated and eluted with the HPLC method described by Gynther et al. (28) The conditions for peptide detection were used as follows: ESI positive ion mode, the source temperature was maintained at $210^{\circ} \mathrm{C}$, drying gas (nitrogen) flow rate was $16 \mathrm{~L} / \mathrm{min}$, nebulizer pressure was $45 \mathrm{psi}$, the MS capillary voltage was $3 \mathrm{kV}$. Dwell time was $20 \mathrm{~ms}$. MRM mode was applied. For the quantitation of the target protein, one unique peptide was chosen according to the in silico peptide selection criteria published by Uchida et al. 2013 (27) with exception to methionine residue included to the structure of peptide. Three MRM transitions for Latl specific peptide corresponding to high intensity fragment ions were selected for a stable isotope-labeled peptide and the unlabeled natural peptide (Table I). Data were acquired using the software Agilent MassHunter Workstation Acquisition (Agilent Technologies, Data Acquisition for Triple Quad., version B.03.01). The data processing and analysis were performed with Skyline v 4.1 software.

\section{Data Analysis}

All statistical analyses were performed using GraphPad Prism v. 5.03 software (GraphPad Software, San Diego, CA, USA). The data is presented as mean $\pm \mathrm{SD}$.

\section{RESULTS AND DISCUSSION}

\section{Lat I mRNA and Protein Expression in Mouse Primary Astrocytes}

Astrocytes are important targets for therapeutic compounds against AD as well as neuroinflammation and as Latl expression and function is important for the intra-brain distribution and particularly uptake of substrate drugs into their target cells, we investigated the effect of LPS induced inflammation and AD-causing mutations in APP and PS1 genes on Lat1 mRNA and protein expression in mouse primary astrocytes. Given that inflammatory reaction and reactive astrogliosis have been recognized as integral parts of $\mathrm{AD}$ pathology, the astrocytes were treated with LPS to activate them. We have previously shown that the LPS treatment of primary astrocytes increases the secretion of IL6 and MCP-1. (29) The elevated levels of these cytokines have also been measured from AD patients. $(30,31)$ The effect of LPS and AD transgenes on Latl mRNA expression was investigated by qRT PCR and protein expression was investigated by quantitative LC-MS/MS based proteomics.

The expression of Lat1 mRNA and protein was seen in both wildtype and $\mathrm{AD}$ transgenic astrocytes with and without LPS-induced inflammation. The Lat $1 \mathrm{mRNA}$ levels were $0.068 \pm 0.022,0.033 \pm 0.036$ and $0.114 \pm 0.054$ (Gapdh normalized expression, mean $\pm \mathrm{SD})$ in vehicle-treated wildtype, LPS-treated wildtype and LPS-treated AD astrocytes, respectively (Fig. 1a). The protein expression in vehicle-treated wildtype, LPS-treated wildtype and LPS-treated transgenic cells were $3.07 \pm 0.92,1.95 \pm 1.25$ and $3.77 \pm 0.91 \mathrm{fmol} / \mu \mathrm{g}$ protein (mean $\pm \mathrm{SD}$ ), respectively (Fig. 1b). Interestingly, there was a trend towards a decrease of both Lat1 mRNA (2.1-fold) and protein (1.6-fold) in the LPS-treated wildtype astrocytes when compared to the vehicle-treated wildtype cells. In contrast, the mRNA (1.7-fold) and protein (1.2-fold)
Table I Standard (St) and Internal Standard (Is) Probe Peptides and MRM Transitions for the LC-MS/MS Analysis of LatI and Glut I

\begin{tabular}{llllllll}
\hline Protein & St/ls & Probe peptide sequence & $\begin{array}{l}\text { Retention time } \\
(\mathrm{min})\end{array}$ & $\begin{array}{l}\text { MRM transitions } \\
(\mathrm{m} / \mathrm{z}) \\
\text { QI }\end{array}$ & Q3-1 & Q3-2 & Q3-3 \\
\hline Latl & St & DMGQGDASNLQQK & 9.6 & 696.3 & 960.4 & 788.4 & 403.2 \\
& Is & DMGQGDASNLQQK* & 9.6 & 700.3 & 968.4 & 796.4 & 411.2 \\
Glutl & St & TFDEIASGFR & 21.3 & 571.8 & 894.4 & 537.3 & \\
& Is & TFDEIASGFR* & 21.3 & 576.8 & 904.4 & 547.3 & \\
\hline
\end{tabular}

* denotes ${ }^{13} \mathrm{C}$ labeled arginine and lysine 

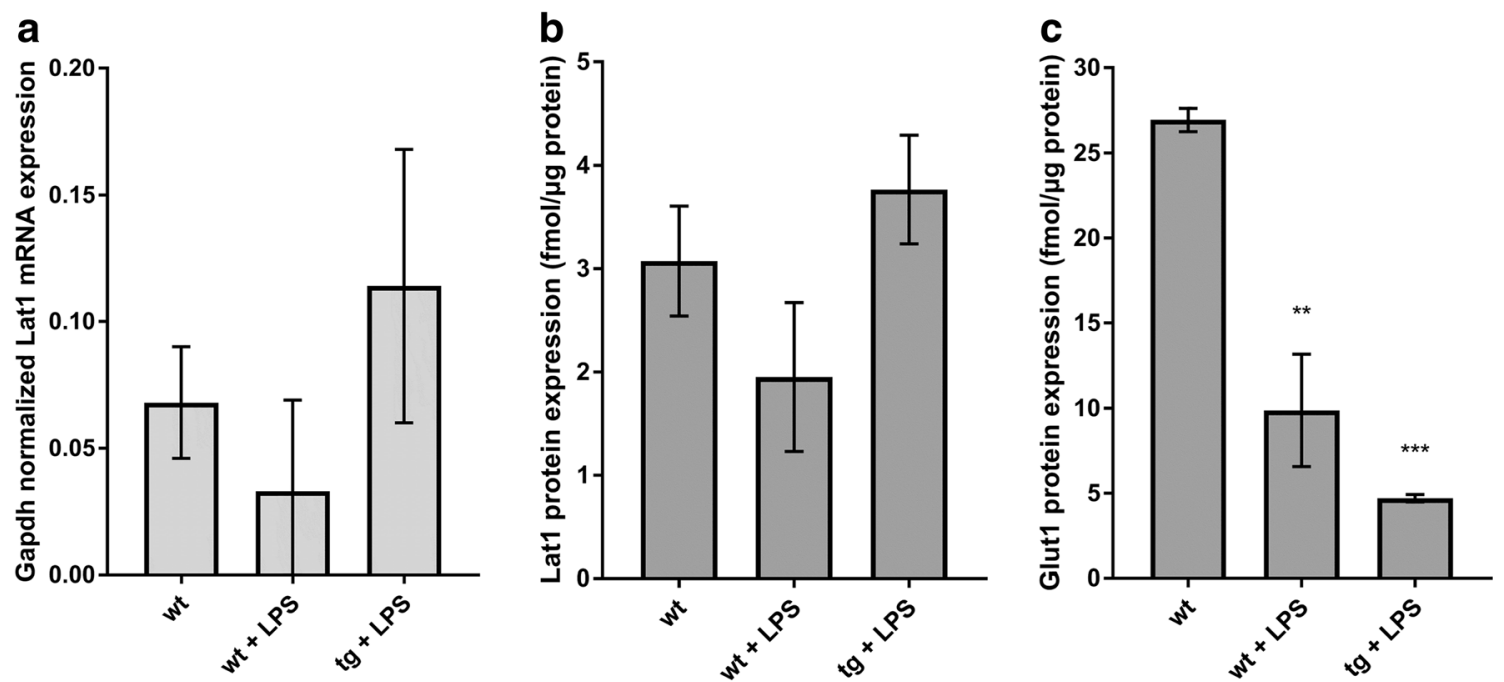

Fig. I The LatI mRNA expression (a) and protein level (b) in wildtype astrocytes with and without LPS treatment and AD transgenic mouse astrocytes with LPS treatment. Glutl protein level (c) in wildtype astrocytes with and without LPS treatment and AD transgenic mouse astrocytes with LPS treatment. The data is presented as mean $\pm \mathrm{SD}, n=3$. The statistical difference between the groups was investigated using one-way ANOVA, followed by Dunnett's test, $* * P<0.0$ I, ***** $<$ <0.001.

expressions were higher in the transgenic astrocytes compared to the wildtype cells, although none of the changes were statistically significant.

In order to confirm the phenotype of the $\mathrm{AD}$ transgenic astrocytes, we determined the protein level of Glutl in the astrocyte samples, as it is known to be downregulated in the astrocytes of $\mathrm{AD}$ brain. (15-17) Unlike Latl protein expression, the Glutl protein expression was significantly decreased in both wildtype cells treated with LPS and in the AD transgenic cells (Fig. 1c). The Glutl protein expression was 26.93 $\pm 1.16,9.87 \pm 5.73$ and $4.70 \pm 0.38 \mathrm{fmol} / \mu \mathrm{g}$ protein $($ mean $\pm \mathrm{SD}$ ), for vehicle-treated wildtype cells, wildtype cells treated with LPS and transgenic astrocytes treated with LPS, respectively. This is in accordance with literature reports of reduced GLUT1 expression in the AD brain. (15-17) However, instead of direct effects, the APP and PS1 mutations should have indirect consequences on astrocyte biology since the mutations are under the control of a prion promoter, which is considered to be primarily neuronal. Although Glutl expression was significantly downregulated in the APP and PS1 transgenic astrocytes compared to the wildtype cells, indicating $\mathrm{AD}$ phenotype, caution has to be used in interpreting these results before confirming them in astrocytes derived from adult mice with $A P P$ and $P S 1$ mutations.

\section{Lat I Function in Mouse Primary Astrocytes}

The function of Latl in AD transgenic and wildtype astrocytes was investigated by measuring the cell uptake of Latl substrate $\left[{ }^{14} \mathrm{C}\right]$-L-leucine (Fig. 2). The Lat1-mediated cell uptake of $\left[{ }^{14} \mathrm{C}\right]$-L-leucine was confirmed by inhibiting the cell uptake by competing Latl substrate L-tryptophan. In both wildtype and $\mathrm{AD}$ astrocytes the presence of $2 \mathrm{mM}$ L-tryptophan reduced the cell uptake of $\left[{ }^{14} \mathrm{C}\right]$-L-leucine significantly by approximately 10 times. The cell uptake of $\left[{ }^{14} \mathrm{C}\right]$-L-leucine was $0.153 \pm 0.058,0.019 \pm 0.005,0.227 \pm 0.043$ and 0.021 $\pm 0.004 \mathrm{nmol} / \mathrm{mg}$ protein (mean $\pm \mathrm{SD}$ ) for wildtype cells, wildtype cells with L-tryptophan, transgenic cells and transgenic cells with L-tryptophan, respectively. In wildtype astrocytes LPS reduced the $\left[{ }^{14} \mathrm{C}\right]$-L-leucine cell uptake by 1.3 -fold $(0.119$ $\pm 0.048 \mathrm{nmol} / \mathrm{mg}$ protein) compared to the non-treated wildtype cells, but the change was not statistically significant. There was no statistically significant difference in leucine uptake between vehicle-treated wildtype cells, wildtype cells

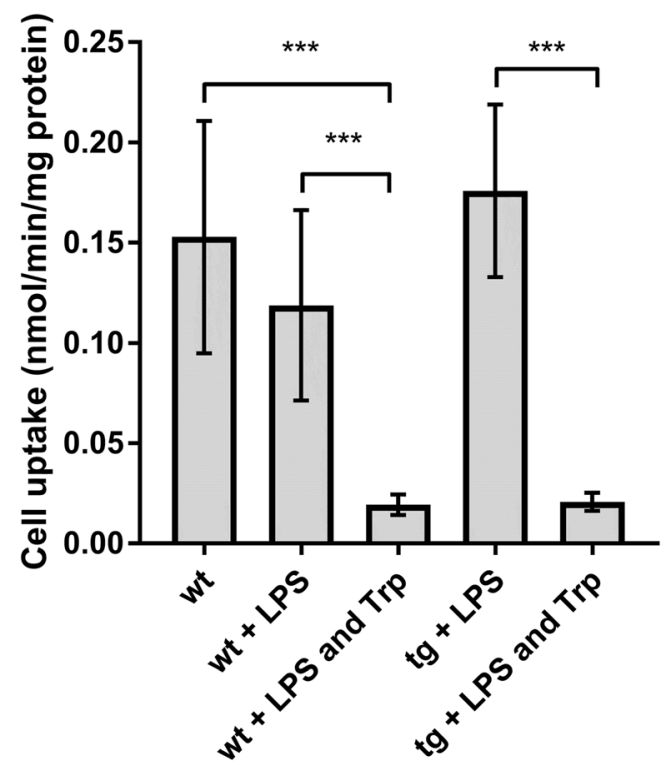

Fig. 2 The cell uptake of $0.157 \mu M\left[{ }^{14} \mathrm{C}\right]$-L-leucine in wildtype and $A D$ astrocytes with and without LPS treatment and presence of $2 \mathrm{mM} \mathrm{L-trypto-}$ phan. The data is presented as mean $\pm S D, n=3$. The statistical difference between the groups was determined using one-way ANOVA, followed by Tukey's test, $* * * * \mathrm{P}<0.001$. 

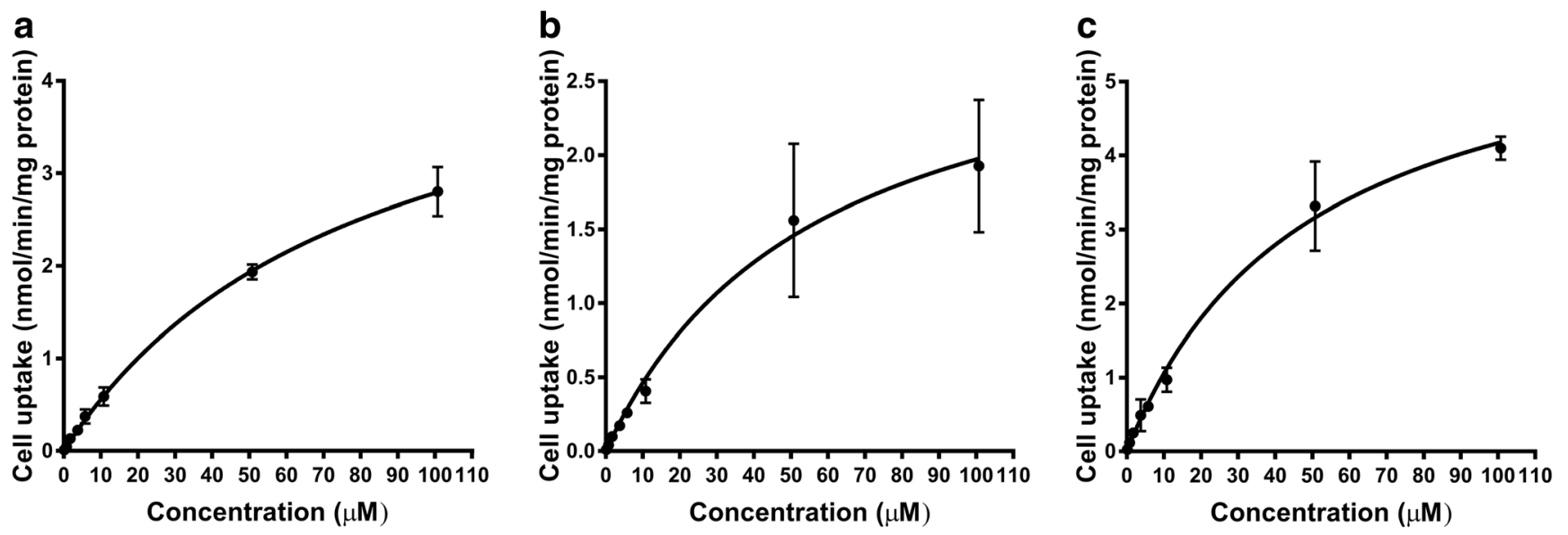

Fig. 3 The concentration dependent cell uptake of for $\left[{ }^{14} \mathrm{C}\right]$-L-leucine in LPS treated AD astrocytes (a), wildtype astrocytes without LPS (b) and wildtype astrocytes with LPS (c). The data is presented as mean $\pm S D, n=3-4$.

treated with LPS and transgenic cells treated with LPS, which is in line with the Latl protein expression results.

The concentration-dependent uptake of $\left[{ }^{14} \mathrm{C}\right]$-L-leucine revealed saturable kinetics (Fig. 3). Neither LPS-induced inflammation nor the presence of $\mathrm{AD}$-causing transgenes altered significantly the function of Latl in mouse primary astrocytes compared to the non-treated wildtype cells (Table II). There was a trend that the uptake capacity via Lat $\left(\mathrm{V}_{\max }\right)$ was decreased in the LPS treated wildtype cells (1.5-fold decrease) and increased (1.3-fold) in the $\mathrm{AD}$ transgenic astrocytes compared to wildtype cells. This is in accordance with the changed Latl expression and cell uptake results.

\section{Lat I Function at the BBB of LPS Treated and AD Transgenic Mice}

We investigated the effect of LPS-induced acute inflammation on the Lat 11 function in mouse cerebral cortex BBB. The mice were injected i.p. with $250 \mu \mathrm{g} / \mathrm{kg}$ of LPS for three consecutive days, a dose and regimen which has been previously shown to induce amylodogenesis and neuroinflammation in mice. (32) However, the dose is not high enough to compromise the tight junction integrity at the BBB and cause paracellular brain permeation of hydrophilic compounds such as amino acids. Banks et al. (33) reported that more than 10-fold higher ( $3 \mathrm{mg} / \mathrm{kg}$ ) dose is required for BBB disruption. The function

Table II The Michaelis-Menten Kinetic Parameters for $\left[{ }^{14} \mathrm{C}\right]$-L-leucine Cell Uptake. The Data is Presented as Mean $\pm S D, n=3-4$. Statistical Significances of Differences Between the Groups were Tested by One-Way ANOVA Followed by Tukey's Test

\begin{tabular}{llll}
\hline & wildtype & wildtype + LPS & transgenic + LPS \\
\hline $\mathrm{V}_{\max }(\mathrm{nmol} / \mathrm{min} / \mathrm{mg})$ & $4.9 \pm 1.3$ & $3.2 \pm 0.9$ & $6.3 \pm 0.3$ \\
$\mathrm{~K}_{\mathrm{m}}(\mu \mathrm{M})$ & $73.3 \pm 17.7$ & $59.7 \pm 18.4$ & $51.6 \pm 11.9$ \\
\hline
\end{tabular}

of Latl at the BBB was investigated using in situ brain perfusion in mice performed $24 \mathrm{~h}$ after the last LPS injection (Fig. 4). The results showed that there were no changes in the BBB permeation rate measured by $\mathrm{K}_{\mathrm{in}}$ values of $\left[{ }^{14} \mathrm{C}\right]$-L-leucine due to LPS-induced neuroinflammation compared to the non-treated control mice. Whereas, co-perfusion of $\left[{ }^{14} \mathrm{C}\right]$-L-leucine with $100 \mu \mathrm{M}$ of selective Latl inhibitor KMH-233 reduced the $\left[{ }^{14} \mathrm{C}\right]$-L-leucine uptake significantly. In addition, we investigated the effect of $\mathrm{AD}$-causing transgenes on Latl function in mouse cerebral cortex and hippocampus using the same method. Interestingly, no changes were observed in the Lat1

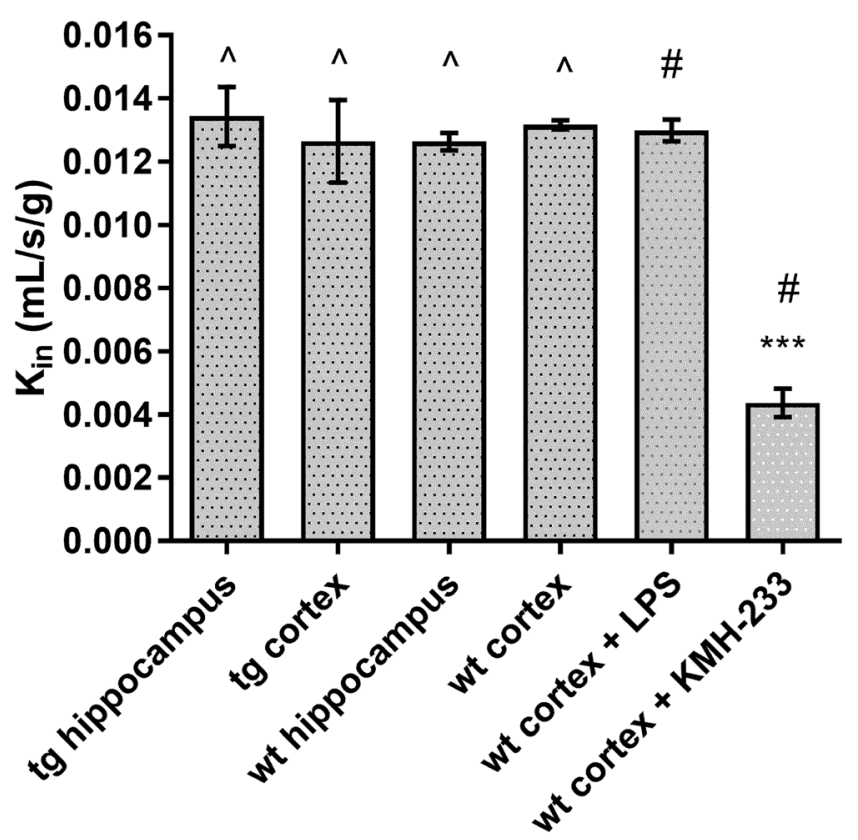

Fig. 4 The $K_{\text {in }}$ values of $\left[{ }^{14} \mathrm{C}\right]$-L-leucine after mouse brain perfusion. The data is presented as mean $\pm S D(n=3-5)$. The statistical difference between the groups was determined using one-way ANOVA, followed by Tukey's test, $* * * P<0.001 . \wedge$ denotes that the mice used in the experiments were $7-$ 8 months old, whereas \# denotes that the mice were 3 months old. 
function compared to the control or LPS treated mice. The lack of LPS effect is in contradiction with the BBB expression results reported earlier. (20) In the study by Wittmann et al., there was significant and time dependent reduction of both Lat $1 \mathrm{mRNA}$ and protein levels at the BBB of LPS treated mice. However, whether the reduction of Latl expression was enough to cause a significant effect in Latl function at the $\mathrm{BBB}$ was not investigated. In the present study the possible changes in Lat 1 protein expression due to LPS-induced inflammation or presence of $\mathrm{AD}$-causing mutations in APP and PS1 genes are not significant enough to affect the function of the transporter at the BBB. Moreover, it has to be noted that the dose and regimen of LPS treatment was different in the present study and the study by Wittmann et al. (20) where the mice were injected once with $2.5 \mathrm{mg} / \mathrm{kg}$. Therefore, there might be differences in the changes of Latl expression at the mouse BBB between these two studies.

\section{CONCLUSIONS}

The results of the present study showed that there were no significant changes in the Latl function at the BBB of LPSinduced inflammation mouse model and AD transgenic mice compared to non-treated wildtype mice. In addition, there were no changes in the mRNA or protein levels in LPStreated wildtype and $\mathrm{AD}$ transgenic primary mouse astrocytes compared to vehicle-treated wildtype astrocytes. Moreover, this is reflected in the unaltered Latl function in the LPStreated and transgenic cells. All together, these data support the view that Lat 1 can be utilized for the delivery of potential $\mathrm{AD}$ drugs across the BBB and astrocyte cell membrane.

\section{ACKNOWLEDGMENTS AND DISCLOSURES}

Open access funding provided by University of Eastern Finland (UEF) including Kuopio University Hospital. The authors would like to thank Mrs. Lea Pirskanen for her technical assistance regarding the in vitro experiments. The present study was financed by Emil Aaltonen Foundation, The Finnish Cultural Foundation (North Savo Regional Fund), the Academy of Finland (grants 257,386, 294,227 and 307,057), and the Biocenter Finland.

Open Access This article is distributed under the terms of the Creative Commons Attribution 4.0 International License (http://creativecommons.org/licenses/by/4.0/), which permits unrestricted use, distribution, and reproduction in any medium, provided you give appropriate credit to the original author(s) and the source, provide a link to the Creative Commons license, and indicate if changes were made.

\section{REFERENCES}

1. Banks WA. From blood-brain barrier to blood-brain inter-face: new opportunities for CNS drug delivery. Nat Rev Drug Discov. 2016;15(4):275-92.

2. Bourasset F, Scherrmann JM. Carrier-mediated processes at several rat brain interfaces determine the neuropharmacokinetics of morphine and morphine-6-beta-D-glucuronide. Life Sci. 2006;78(20):2302-14.

3. Fridén M, Gupta A, Antonsson M, Bredberg U, HammarlundUdenaes M. In vitro methods for estimating unbound drug concentrations in the brain interstitial and intracellular fluids. Drug Metab Dispos. 2007;35:1711-9.

4. Kesselheim AS, Hwang TJ, Franklin JM. Two decades of new drug development for central nervous system disorders. Nat Rev Drug Discov. 2015;14(12):815-6.

5. Gabathuler R. Approaches to transport therapeutic drugs across the blood-brain barrier to treat brain diseases. Neurobiol Dis. 2010;37(1):48-57.

6. Kanai Y, Segawa H, Miyamoto K, Uchino H, Takeda E, Endou $H$. Expression cloning and characterization of a transporter for large neutral amino acids activated by the heavy chain of 4F2 antigen (CD98). J Biol Chem. 1998;273(37):23629-32.

7. Kageyama T, Nakamura M, Matsuo A, Yamasaki Y, Takakura Y, Hashida M, et al. The 4F2hc/LAT1 complex transports L-DOPA across the blood-brain barrier. Brain Res. 2000;879(1-2):115-21.

8. Uchino H, Kanai Y, Kim DK, Wempe MF, Chairoungdua A, Morimoto E, et al. Transport of amino acid-related compounds mediated by L-type amino acid transporter 1 (LAT1): insights into the mechanisms of substrate recognition. Mol Pharmacol. 2002;61(4):729-37.

9. Gynther M, Jalkanen A, Lehtonen M, Forsberg M, Laine K, Ropponen J, et al. Brain uptake of ketoprofen-lysine prodrug in rats. Int J Pharm. 2010;399(1-2):121-8.

10. Gynther M, Pickering DS, Spicer JA, Denny WA, Huttunen KM. Systemic and brain pharmacokinetics of perforin inhibitor prodrugs. Mol Pharm. 2016;13(7):2484-91.

11. Gynther M, Peura L, Vernerová M, Leppänen J, Kärkkäinen J, Lehtonen M, et al. Amino acid Promoieties Alter Valproic acid pharmacokinetics and enable extended brain exposure. Neurochem Res. 2016;41(10):2797-809.

12. Puris E, Gynther M, Huttunen J, Petsalo A, Huttunen KM. L-type amino acid transporter 1 utilizing prodrugs: how to achieve effective brain delivery and low systemic exposure of drugs. J Control Release. 2017;261:93-104.

13. Boado RJ, Li JY, Nagaya M, Zhang C, Pardridge WM. Selective expression of the large neutral amino acid transporter at the bloodbrain barrier. Proc Natl Acad Sci U S A. 1999;96:12079-84.

14. Duelli R, Enerson BE, Gerhart DZ, Drewes LR. Expression of large amino acid transporter LAT1 in rat brain endothelium. J Cereb Blood Flow Metab. 2000;20:1557-62.

15. Liu Y, Liu F, Iqbal K, Grundke-Iqbal I, Gong CX. Decreased glucose transporters correlate to abnormal hyperphosphorylation of tau in alzheimer disease. FEBS Lett. 2008;582(2):359-64.

16. Winkler EA, Nishida Y, Sagare AP, Rege SV, Bell RD, Perlmutter $\mathrm{D}$, et al. GLUT1 reductions exacerbate Alzheimer's disease vasculoneuronal dysfunction and degeneration. Nat Neurosci. 2015;18(4): 521-30.

17. Mooradian AD, Chung HC, Shah GN. GLUT-1 expression in the cerebra of patients with Alzheimer's disease. Neurobiol Aging. 1997;18:469-74.

18. Jankowsky JL, Fadale DJ, Anderson J, Xu GM, Gonzales V, Jenkins NA, et al. Mutant presenilins specifically elevate the levels of the 42 residue beta-amyloid peptide in vivo: evidence for augmentation of a 42-specific gamma secretase. Hum Mol Genet. 2004;13(2):159-70. 
19. Vellonen KS, Ihalainen J, Boucau MC, Gosselet F, Picardat T, Gynther $\mathrm{M}$, et al. Disease-induced alterations in brain drug transporters in animal models of Alzheimer's disease. Pharm Res. 2017;34(12):2652-62.

20. Wittmann G, Mohácsik P, Balkhi MY, Gereben B, Lechan RM. Endotoxin-induced inflammation down-regulates L-type amino acid transporter 1 (LAT1) expression at the blood-brain barrier of male rats and mice. Fluids Barriers CNS. 2015;12:21.

21. González-Reyes RE, Nava-Mesa MO, Vargas-Sánchez K, ArizaSalamanca D, Mora-Muñoz L. Involvement of astrocytes in Alzheimer's disease from a Neuroinflammatory and oxidative stress perspective. Front Mole NeuroSci. 2017;10:427.

22. Su TZ, Lunney E, Campbell G, Oxender DL. Transport of gabapentin, a gamma-amino acid drug, by system 1 alpha-amino acid transporters: a comparative study in astrocytes, synaptosomes, and CHO cells. J Neurochem. 1995;64(5):2125-31.

23. Wang Y, Welty DF. The simultaneous estimation of the influx and efflux blood-brain barrier permeabilities of gabapentin using a microdialysispharmacokinetic approach. Pharm Res. 1996;13(3):398-403.

24. Huttunen KM, Gynther M, Huttunen J, Puris E, Spicer JA, Denny WA. A selective and slowly reversible inhibitor of l-type amino acid transporter 1 (LAT1) potentiates Antiproliferative drug efficacy in Cancer cells. J Med Chem. 2016;59(12):5740-51.

25. Pihlaja R, Koistinaho J, Malm T, Sikkilä H, Vainio S, Koistinaho M. Transplanted astrocytes internalize deposited beta-amyloid peptides in a transgenic mouse model of Alzheimer's disease. Glia. 2008;56(2):154-63.

26. Muller PY, Janovjak H, Miserez AR, Dobbie Z. Processing of gene expression data generated by quantitative real-time RT-PCR. BioTechniques. 2002;32(6):1372-4 1376, 1378-9.
27. Uchida Y, Tachikawa M, Obuchi W, Hoshi Y, Tomioka Y, Ohtsuki S, et al. A study protocol for quantitative targeted absolute proteomics (QTAP) by LG-MS/MS: application for inter-strain differences in protein expression levels of transporters, receptors, claudin-5, and marker proteins at the blood-brain barrier in ddY, FVB, and C57BL/6J mice. Fluids Barriers CNS. 2013;10:21.

28. Gynther M, Proietti Silvestri I, Hansen JC, Hansen KB, Malm T, Ishchenko $\mathrm{Y}$, et al. Augmentation of anticancer drug efficacy in murine hepatocellular carcinoma cells by a peripherally acting competitive N-methyl-d-aspartate (NMDA) receptor antagonist. J Med Chem. 2017;60(23):9885-904.

29. Choo XY, Liddell JR, Huuskonen MT, Grubman A, Moujalled D, Roberts J, et al. CuII(atsm) Attenuates Neuroinflammation. Front Neurosci. 2018;12:668.

30. Rothaug M, Becker-Pauly C, Rose-John S. The role of interleukin6 signaling in nervous tissue. Biochim Biophys Acta. 2016;1863(6 Pt A): $1218-27$.

31. Lee WJ, Liao YC, Wang YF, Lin IF, Wang SJ, Fuh JL. Plasma MCP-1 and cognitive decline in patients with Alzheimer's disease and mild cognitive impairment: a two-year follow-up study. Sci Rep. 2018;8:1280.

32. Lee JW, Lee YK, Yuk DY, Choi DY, Ban SB, Oh KW, et al. Neuro-inflammation induced by lipopolysaccharide causes cognitive impairment through enhancement of beta-amyloid generation. J Neuroinflammation. 2008;5:37.

33. Banks WA, Gray AM, Erickson MA, Salameh TS, Damodarasamy $\mathrm{M}$, Sheibani N, et al. Lipopolysaccharide-induced blood-brain barrier disruption: roles of cyclooxygenase, oxidative stress, neuroinflammation, and elements of the neurovascular unit. J Neuroinflammation. 2015;12:223. 